\title{
MEANS AND METHODS OF EXPRESSING THE SENSES IN ENGLISH PREFIXAL VERBS
}

\author{
Anna Dudok \\ Postgraduate Student, Ivan Franko National University of Lviv, Ukraine \\ e-mail: annadudok1995@ukr.net,orcid.org/0000-0001-5588-9538
}

\section{Summary}

The paper dwells upon the systematic description of English verbal prefixes. The verbal prefix is to be treated in the paradigmatic and syntagmatic plane of the language. It is asserted in this article that the meaning of a prefix is identical to that of the preposition - the relationship between two objects in space extrapolating on two consecutive states of the subject/object in time, and when generalized, form the two types of senses. Such prefix features as origin, transporting opportunity, negation and valency are considered, as well as semantic features (such as polysemy and chains of synonyms). In semantic analysis we deal with semes as the meaning constituents defining basic and secondary semes. The process of the formation of different senses has been distinguished by means of semantic opposition and combinations of semes that form the invariant meaning of the verbal prefix.

Keywords: prefix, word-building, meaning, senses, verbal prefix, componential analysis, semantic opposition, invariant.

DOI: https://doi.org/10.23856/4202

\section{Introduction}

Looking at the English prefixes in general it can be easily noticed that through a brief history of English derivational system, prefixes confirm our assumption that the change of English derivational system have led not only to make a distinction between native and foreign prefixes, but also to make a distinction between general and specific prefixes their meaning. While the first distinction is a common one, the second needs some explanation. Namely, we have noticed that the range of prefix senses includes pure logical meaning of contrary and contradictory semantic oppositions on one hand, which we have called general invariant, and on the other hand the numerous prefix semes, which we have called specific or differential ones.

In branch of lexicology a prefix is generally defined as an affixal morpheme that follows the word-building stem (Barhudarov, 2009). To characterize the prefixal verb inventory it is necessary first to estimate its semantic and structural components. Generally speaking, verbal prefixes can be classified into productive and non-productive. According to P.M. Karaschuk there exist 14 productive prefixes, pointing out also 57 less productive (Karashhuk, 1977).

In this paper we consider the generalized invariant verbal meaning and their semantic features called semes or senses. The theoretical significance of the article is based on the importance of the singling out the invariant meaning in the plane of language and the number of different sense in the plane of speech. Practical significance is explained by the importance of finding out semantic generalized and specified features of the prefixal verbs in teaching word-building and semasiology. To describe the componential elements of the prefixal verbs we will take the criteria described by O.D. Meshkov (origin, transporting opportunity, negation, valency) (Meshkov, 1975). 
We support the linguistics, asserting that English prefixes are affixes (i.e., bound morphemes that provide inner lexical meaning) that are added before either simple roots or complex bases (or operands) consisting of (a) a root and other affixes, (b) multiple roots, or (c) multiple roots and other affixes. Examples of these follow: undo (consisting of prefix $u n$ - and root $d o$ ).

It is supposed that In English, all verbal prefixes are derivational by their functional meaning possessing their general invariant meaning and a range of differential senses.

\section{The applied methodology in studying meaning and senses of English Prefixes}

Firstly. The method of studying the prefixal verb in English, particularly is applied to isolate invariant value in the language system and a number of elementary semes - senses, which function as semantic differential features in the speech system. The main methods are involved in the study of prefixal verbs including the method of word formation in structural and semantic dimensions, componential analysis and analysis of vocabulary definitions.

The applied technique of meaning - sense is made it possible to distinguish several diverse components of the invariant value in the language system and the variable component (sense) in speech. Both the theoretical and practical meanings of the mechanism's different senses formation in the prefixal verb applies to identification of the semantic invariant. Its role in the generation of every subsequent meaning has been also clarified. Revealing the factors of the different meanings' prefix verb generation lies both in its generalized free - flowing nature and the creative combination of the thinking process. The possibility of formation different quantitative and qualitative combinations in one family and the neutralization of others, increases the meaning - prefix verb's forming power and conversely the constant simultaneous functioning of all invariant values that limits the possibility of its meaning creation.

Secondly. English prefixal verbs are characterized by semantic phenomena in polysemy, synonymy and antonymy, which conditioned by the peculiarity of modern English terminology and the promotion of a clear boundary in the professional language between general verb vocabulary and lexicon. The analysis of empiric material has shown that there is a tendency to diminish the role of Romance and to increase the proportion of German verb prefixes in modern English. The article summarizes the meaning of the prefix verb as the result of a creative act thinking, that is, the combination of two diverse semantic components: a variable labeled member of the semantic opposition in the plane of speech that is syntagmatic and its invariant meaning marker from the paradigmatic plane of language.

Thirdly. We confirm the accepted definition that a prefix (affix) is a word, or letter(s) placed at the beginning of another word (a base word) to adjust or qualify its usage or meaning. Understanding the meanings of the common prefixes can help us to deduce the meanings of new words, in our case numerous senses of analyzed verbal prefixes. In dealing with prefixes we proceede from two points; first - the prefix as a respective (identical) preposition, denote a certain type of relationship between two objects; second - any word (even a morpheme) has its own invariant paradigmatic meaning and a syntagmatic sense when used in speech: below is the table that defines and illustrates the most common verbal prefixes supplied with examples; it helps the reader to understand the functional communicative potential of the verbal prefixes.

The following Table 2 shows the list of English prefixes with their general meaning and expliciting different senses. 
Verbal prefixes and their sense potential

\begin{tabular}{|c|c|}
\hline PREFIX & EXAMPLE \\
\hline \multicolumn{2}{|c|}{ The opposite, a negative or reverse } \\
\hline un- (not/reverse action) & unavoid \\
\hline ub- (reverse action) & abdicate \\
\hline de- (reverse action) & decompound \\
\hline dis-/di-/dif- (apart) & dishonest \\
\hline im- (not/reverse action) & immature \\
\hline \multicolumn{2}{|c|}{ Degree and quality } \\
\hline under- (lower in grade/dignity) & underestimate \\
\hline sub- (below, under) & subscribe \\
\hline up- (higher or better) & upgrade \\
\hline \multicolumn{2}{|c|}{ Time } \\
\hline post- (after, behind) & post-graduate \\
\hline pre- (before) & pre-elect \\
\hline \multicolumn{2}{|c|}{ Size } \\
\hline maxi- (very long, very large) & maximize \\
\hline mini- (small) & minimize, minify \\
\hline mega- (great, large) & megaphone \\
\hline micro- (small) & microstructure \\
\hline
\end{tabular}

Table 2

Central invariant meaning and peripheral senses of prefixal verbs with examples 1. Semantic classification:
a) negative prefixes
b) prefixes denoting repetition or reversative actions
c) prefixes denoting time, space, degree relations in-, un- (not/reverse action) $d e-, r e-$, dis- (decolonize, revegetate, disconnect) inter-, hyper-, ex-, pre-, over- (intersect, hyperoxidize, pre-elect, overdrug)

\section{Prefixal origin:}
a) native (Germanic)
b) Romantic over-, under- (overfeed, undernourish) in-, de-, ex-, re- (incurve, demilitiraze, exterminate, rewrite)
c) Greek sym-, hyper- (sympathize, hypertense)

\section{The function of prefixes: convertive and non-convertive:}
a) convertive prefixes transfer derivatives to a different part of speech in comparison with their original stem
b) non-convertive prefixes em-, de- (bronze - to embronze; bus - to debus) to go - undergo; easy - uneasy) dis-, under-, un (to agree - to disagree;

\section{Stylistic value:}
a) stylistically neutral
b) literary bookish un-, over-, re- (unriddle, oversee, resell) ultra-, bi- (ultramodern, biform)

5. The grammatical type of the stem prefixes combine with:
a) deverbal
re-, over-, out- (rewrite, overdo, outstay) 
The main idea is that each prefix has its own meaning, hence possesses its own invariant meaning, which realizes the function of differentiation and graduation to create new senses. The analyzed prefixes are quite productive and the number of derived verbs are predominant in Modern English language. Thus, the central invariant is realized with its meaning in language, while it obtains a new peripheral sense in speech.

Table 3

The meaning of the verbal prefixes constituents defining basic and secondary semes following with examples

\begin{tabular}{|c|c|c|}
\hline PREFIX & MEANING & EXAMPLE \\
\hline $\mathrm{CO}-$ & joint, with, accompanying & co-work, coordinate, cooperate \\
\hline$d e-$ & reverse action, get rid of & de-emphasize, devocalize, depress \\
\hline dis- & not, opposite of & disagree, disapprove, dislike \\
\hline dis- & reverse action, get rid of & disconnect, disinform \\
\hline fore- & before, in front & forearm, forecast, forego \\
\hline mis- & wrong, astray & misinform, misguide, misbehave, misspell \\
\hline over- & excessive, above & overreact, overact, overbear \\
\hline post- & after, behind & post-elect, post-graduate, post-date \\
\hline pre- & before & precast, pre-exist, predominate \\
\hline pro- & for, forward in, in favor of & procreate, proscribe, prorogue \\
\hline re- & again, back & redo, revisit, rerun, reorganize \\
\hline un- & not, against, opposite of & unarm, uncage, unroof, \\
\hline un- & reverse action, deprive of, release from & undo, untie, unlock \\
\hline under- & $\begin{array}{l}\text { below, beneath, lower in grade or } \\
\text { dignity, lesser, insufficient }\end{array}$ & underact, underpay, undergo \\
\hline up- & greater, higher or better & upgrade, uplift, upheave \\
\hline with- & against, back, away (from) & withstand, withhold, withdraw \\
\hline
\end{tabular}

The analysis of the researched verbal prefixes has been conducted on the basis of explanatory English language dictionaries and the Word Net electronic resourses accepting the prefixal verbs as a unit of the research. It is noticed that verbs of Germanic origin prevail in the correlations of objects in space/ whereas prefixes of Roman origin (co-, pre-, pro-, etc) are mostly obsolete in their meaning and merge with verbs to function in special senses, their root verbs normally do not function separately (Meyer, 2009).

\section{Prefixal inventory of modern English}

While speaking about prefixes, it is worth mentioning the important role of borrowings. According to statistics 6 out of 14 productive prefixes are borrowed predominantly from Latin and Greek. Due to numerous researchers English prefixes are generally non-transportive. Their main function is, accordingly to change the lexical rather than grammatical meaning of the productive stem. However, V.I. Shkarupin comes up with another point of view. He points out two groups of English transportive prefixes:

1. verb-forming from nouns and adjectives: be-, de-, dis-, enlin-, inter-, out-, over-, re-, un;

2. adjective-forming from nouns, word combinations and participles: anti-, inter-, intra-, multi-, over-, poly-, post-, pre-, pro-, sub-, super-, supra-, un-, under-(Shkarupin, 1963: 146-154). 
Still it is important to consider the fact that many (however, not all) of the above mentioned prefixes form words of a different part of speech in case of the simultaneous conversion. For example, it is possible to form an adjective underwater by prefixation with under- from the stem water. However, it will be the conversed stem of an adjective (as there is a word combination water transport in English).

It's worth noting in our article that such phenomena as negation and valency are typical features for a huge share of verbal prefixes. A huge number of negative prefixes enhances the important role of prefixation as a way of changing lexical meaning of prefixal verbs.

Most productive verbal prefixes have single valency that can be outlined within two types: verbal and adjectival. Comparison characteristics shows that single-valency productive prefixes $33 \%$ are adjectival, $67 \%$ - verbal. The chart below illustrates the data:
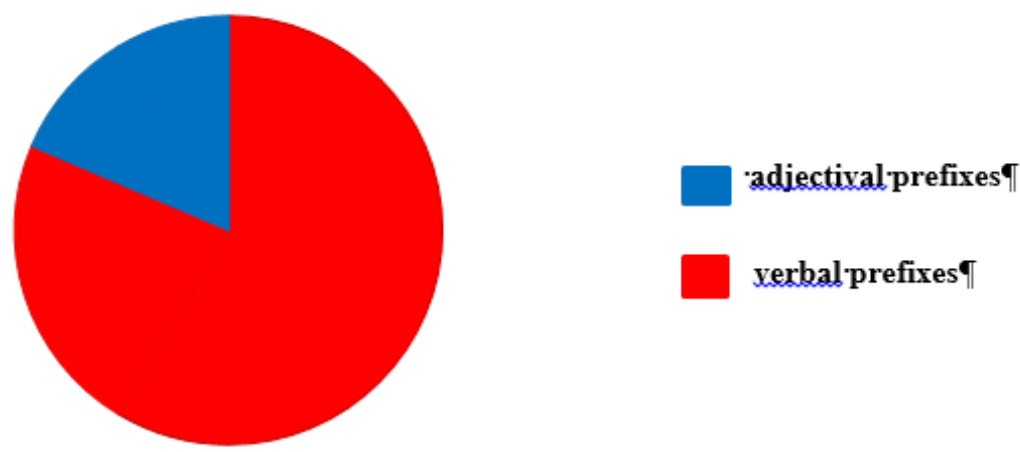

\section{Fig 1. Comparison of single valency within adjectival and verbal prefixes}

To determine the nature of negative verbal prefixes we have used two criteria, the origin of the prefix/base and the range of conveyed senses. We have analyzed the following list of negative verbal prefixes in Modern English language which are as follows: un-, dis-, de-, in-, $a-$, non- and mis- (Thomas, 2008), etc.

The criterion we have also used when comparing negative prefixes, but which has no influence on our list, is the range of their application, i.e. the class of words they are added to. This criterion is used to determine the productivity of a negative prefix and not its "nature". We use the unique definitions for the basic notions like word, word formation, prefixes, and productivity as defined by Marchand (Marchand, 1960).

We have structured our paper, respecting the two lines that we follow, into three sections in accordance with usual division of the history of English Language, Old, Middle and Modern. Each section contains the presentation of derivational patterns, particularly prefixing, features of negative prefixes, and the relation between prefix un- and other negative prefixes in the particular period. The fourth section is the conclusion, where we also give some suggestions for a further research.

\section{Derivation in Modern English and features of native and foreign negative prefixes}

The great number of borrowed words, particularly, foreign derivational affixes, patterns and functional words was the heritage of MdE. The process of borrowings continued but now 
only "the parts of words, affixes, of which some are prefixes, and some suffixes" were borrowed. from Greek and Latin. In this situation, the vocabulary of Modern English augmented enormously, but with few exceptions classical roots serve to express even simple ideas. When suffixing is still more productive with nouns and adjectives prefixing is more productive with verbs, i. g. prefix $a$ - presents the Greek prefix:

English coinage are all derivatives from nominal bases but are practically interpreted as opposites of unprefixed adjectives.

- prefix non- originates from Latin Law, i.e. from the model non-creditor used for coining new nouns. Today, it can be prefixed to almost any adjective, present and participles used as adjectives. It shows immense productivity, but cannot be used with verbs.

- prefix de- has always formed denominal verbs with privative meaning, and deverbal verbs with reversative meaning in French. Its range of application is restricted to verbs, mainly denominative, as in defrost, dethrone, defrock. It conveys logical meaning as in debate, and practical of "remove from, diminish", as in dehydrate, demolish, depreciate.

- prefix un- competes with non- when adjectives are in question, and it seems that nonpattern is becoming more productive. Regarding verbs, it is more productive than prefix dewhen conveying the meaning "reversal", but has lost when conveying the meaning of "deprived of", as in decapitate, defraud.

Thus, we may confirm, that all foreign verbal negative prefixes convey logical meaning into bases where:

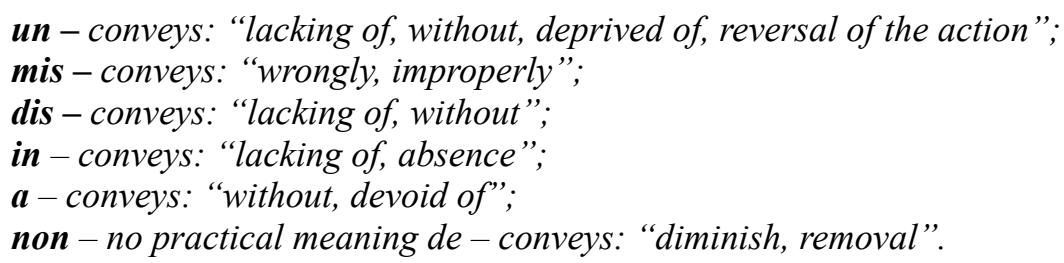

Thus, a detailed inventory of the highly pruductive prefixal negative verbs has been drawn and the sense constituents of the lexical-semantic group have been examined in terms of paradigmatic relations.

\section{Conclusions}

Prefixation is the formation of words by means of adding a prefix to the stem. In English it is characteristic for forming verbs. The main function of prefixes in English is to change the lexical meaning of the same part of speech.

The conclusion is that each verbal prefix possesses its own invariant meaning which realizes the function of differentiation and graduation to create new senses. About forty per cent of the considered verbal prefixes make up a chain of synonyms. This phenomenon can be explained by the fact that many productive verbal prefixes are derived from prepositions. Verbal prefixes are transportive, that supports the theory of lexical rather than grammatical meaning of prefixes. Further on the paper considers the comparison of adjectival and verbal prefixes. The result of this work will be useful in the design of theoretical courses used in Lexicology, Semasiology and Lexicography. The prefixal verbs of the Germanic and Roman origin realize their word-building productivity and valency in the formation of verbs. The difference between the preposition and the identical verb prefix lies only in the plane of functioning. The verbal prefix is to be treated in the paradigmatic and syntagmatic plane of the language. A distinction has been made between language and speech, and meaning in language and senses in speech/ 
The opposition method and method based on meaning and sense reveals the mechanism responsible for generating various senses of the verbal prefix.

Research results reveal prospects for further study of verbal prefixes from the standpoint of semantic, conceptual and functional approaches.

\section{References}

Barhudarov L. S. (2009) Ocherki po morfologii sovremennogo anglijskogo jazyka [Studies on morphology of modern English]. Moskva. [in Russian]

Karashhuk P. M. (1977) Slovoobrazovanie anglijskogo jazyka [Word formation of English]. Moskva: Vysshaja shkola. [in Russian]

Meshkov O. D. (1975) Slovoobrazovanie sovremennogo anglijskogo jazyka [Word formation of modern English]. Moskva: Nauka. [in Russian]

Meyer Ch. F. (2009) Introducing English linguistics. Cambridge: Cambridge University Press. Marchand Hans (1960) The Categories and Types of Present-Day English Word-Formation. Wiesbaden: Otto Harrassowitz.

Shkarupin V. I. (1963) On the specifics of prefixing in modern English. Problems of the Germanic languages morphological structure. pp. 146-154. Moscow: Publishing House of the USSR Sciences Academy.

Thomas Tsoi (2008) Etymology, Morphology, Phonology, Semantics. So many negative prefixes. Retrieved from: http://www.linglish.net/2008/09/15/so-many-negative-prefixes 